\title{
Propagation, Proximate and Fatty Acid Compositions of Rotifer Brachionus plicatilis Fed on Yeast Cultured in Sea Water Containing Liquid from Mackerel Waste Juice*1
}

\author{
Md. Abul Hossain, ${ }^{* 2}$ Masayuki Furuichi, ${ }^{* 2}$ and Yasuo Yone ${ }^{* 2}$ \\ (Received March 19, 1988)
}

\begin{abstract}
Rotifer was fed on yeast (WY) cultured sea water containing liquid from mackerel waste juice, and its growth was compared with rotifer fed on commercial baker's yeast (BY). Furthermore, proximate and fatty acid compositions of rotifer reared with WY yeast were compared with those of rotifer reared with BY yeast, $\omega$-yeast $(\omega \mathrm{Y})$ or marine chlorella. A similar density and harvest of rotifer were obtained by cultivation with both WY and BY yeasts. Rotifer fed on WY yeast showed higher ash content than that of rotifer fed on BY yeast, $\omega$-yeast or marine chlorella, but similar moisture, protein, and lipid contents to the groups fed on BY yeast and marine chlorella. On the other hand, rotifer reared with $\omega$-yeast showed high lipid and low protein contents as compared with those of rotifer reared with WY yeast, BY yeast or marine chlorella. The percentage of $\omega 3$ HUFA in total fatty acids of lipid from rotifer reared with WY yeast was similar to that of BY group, but lower than that of $\omega \mathrm{Y}$ and marine chlorella groups.
\end{abstract}

In the previous studies, ${ }^{1,2)}$ it was found that yeast Saccharomyces cerevisiae IFO 2114 grew well in $75 \%$ sea water containing $2.5 \%$ liquid (water soluble fraction) of juice from pressed mackerel waste and $1 \%$ molasses (WY medium), ${ }^{1)}$ and enough yeast to feed rotifers in 1 ton tank $(150-200 \mathrm{indiv} . / \mathrm{m} l)$ for a day or more propagated with a moderate density in $15 l$ culture medium. However, the $\omega 3$ HUFA $^{* 3}$ content of yeast (WY) cultured in the WY medium was far lower than that of $\omega$-yeast (Kyowa Hakko Kogyo Co. Ltd., $\omega \mathrm{Y}^{3)}$ and marine chlorella Chlorella minutissima. Accordingly, it is doubtful whether WY yeast is suitable to feed rotifer or not.

In the present investigation, the growth of rotifer fed on WY yeast was compared with that of rotifer fed on commercial baker's yeast (BY). Furthermore, proximate and fatty acid compositions of rotifer fed on WY yeast were compared with those of rotifer fed on BY yeast, $\omega$-yeast or marine chlorella.

\section{Materials and Methods}

\section{Liquid}

The water soluble fraction (liquid) of juice from pressed mackerel waste was obtained by the same method as that described in the previous paper. ${ }^{1)}$

\section{Yeast Culture}

Yeast Saccharomyces cerevisiae IFO 2114 was cultured in $75 \%$ sea water containing $2.5 \%$ liquid and $1 \%$ molasses in a $30 l$ tank under the same optimum conditions as those described in the previous paper. $^{2)}$

\section{Rotifer Seed}

Rotifer Brachionus plicatilis fed on BY yeast was used as a seed. The density of rotifer seed was approximately 157 indiv./ml, with $33 \%$ fecundity ( $\%$ of individual with $\mathrm{egg}$ ).

\section{Cultivation and Feeding}

Two transparent polyvinyl tanks of 1 ton capacity were used to rear rotifer with WY or BY yeasts in a vinyl house. The tanks were filled with sand and cotton filtered sea water and aerated. Water temperature was maintained at $24-26^{\circ} \mathrm{C}$. Rotifer seed in $51 l$ was strained out through $60 \mu$ mesh plankton net and a half of the strained rotifer was divided into 2 tanks with equal wet weight, and consequently each tank got approximately 2 indiv. $/ \mathrm{m} l$ of rotifer. The remainder half of the strained rotifer was washed with water and cen-

*1 Contribution from Fish. Res. Lab., Kyushu University, No. 175. Studies on Utilization of Fish Waste-9.

*2 Fishery Research Laboratory, Kyushu University, Tsuyazaki, Fukuoka 811-33, Japan (モハメト ブル ホセイン, 古市政幸, 米康夫: 九州大学農学部附属水産実験所).

$* 3 \omega 3$ highly unsaturated fatty acids. 
Table 1. Growth anf fecundity of rotifer fed on backer's yeast (BY) and yeast cultured in sea water containing liquid and molasses (WY)

\begin{tabular}{|c|c|c|c|c|c|c|c|c|}
\hline \multirow{2}{*}{ Days } & \multicolumn{2}{|c|}{$\begin{array}{l}\text { Yeast fed } \\
(\mathrm{g})\end{array}$} & \multicolumn{2}{|c|}{$\begin{array}{l}\text { Density of rotifer } \\
\text { (Indiv./m } l \text { ) }\end{array}$} & \multicolumn{2}{|c|}{ Fecundity* } & \multicolumn{2}{|c|}{$\begin{array}{l}\text { Water temperature } \\
\left({ }^{\circ} \mathrm{C}\right)\end{array}$} \\
\hline & BY & WY & BY & WY & BY & WY & BY & WY \\
\hline 0 & 40 & 40 & 2 & 2 & 33 & 33 & 23.9 & 24.0 \\
\hline 1 & 40 & 40 & 17 & 15 & 26 & 21 & 25.0 & 25.0 \\
\hline 2 & 40 & 40 & 21 & 20 & 17 & 19 & 25.5 & 25.2 \\
\hline 3 & 40 & 40 & 31 & 32 & 27 & 31 & 25.7 & 25.8 \\
\hline 4 & 50 & 50 & 40 & 37 & 25 & 28 & 25.5 & 25.6 \\
\hline 5 & 75 & 75 & 64 & 69 & 32 & 38 & 26.0 & 26.0 \\
\hline 6 & 120 & 120 & 103 & 131 & 35 & 42 & 26.1 & 26.0 \\
\hline 7 & 180 & 180 & 156 & 175 & 49 & 41 & 26.2 & 25.9 \\
\hline 8 & 220 & 220 & 212 & 209 & 35 & 48 & 26.1 & 26.0 \\
\hline 9 & 350 & 350 & 290 & 303 & 40 & 37 & 26.0 & 26.0 \\
\hline 10 & 420 & 420 & 351 & 378 & 29 & 31 & 26.1 & 26.1 \\
\hline
\end{tabular}

* \% of individual with egg.

trifuged at $2,000 \mathrm{rpm}$ for $10 \mathrm{~min}$, and weighed to calculate total amount of rotifer added to each tank.

A certain amount of yeast (WY or BY) was fed daily to rotifer twice a day depending on its density, as shown in Table 1 . The density and fecoundity of rotifer were counted daily after adding a few drops of formaline with a stereomicroscope and a plankton counting plate. The cultivation was continued for 11 days. Feces and suspended materials in the rearing tank were strained out through a polyvinyl sponge-mat hanged inside of a tank, and the sponge-mat was washed daily. After cultivation rotifer was harvested, washed, centrifuged and weighed.

\section{Analytical Methods}

Rotifer seed reared with BY yeast was further fed on $\omega$-yeast $(\omega \mathrm{Y})$ or marine chlorella $(\mathrm{C})$ for 10 days. Rotifers of $\omega \mathrm{Y}$ and $\mathrm{C}$ were presented to the determination of proximate compositions together with WY and BY rotifers. The analytical methods were the same as those described in the previous study." The fatty acid compositions of lipids in rotifers fed on yeasts and marine chlorella were also determined by the method mentioned previously, ${ }^{5)}$ except for $175^{\circ} \mathrm{C}$ column temperature in GLC operating conditions.

\section{Results and Discussion}

\section{Growth}

Both rotifers fed on WY and BY yeasts showed similar density and fecundity, as shown in Table 1. The harvest (total weight) of both rotifers at
Table 2. Proximate composition of rotifer fed on baker's yeast (BY), WY, $\omega$-yeast $(\omega Y)$ and marine chlorella (C)

\begin{tabular}{lcccc}
\hline \multirow{2}{*}{ Composition } & \multicolumn{4}{c}{ Feeds } \\
\cline { 2 - 5 } & BY & WY & $\omega Y$ & \multicolumn{1}{c}{ C } \\
\hline Moisture (\%) & 89.5 & 89.3 & 87.1 & 90.2 \\
Lipid* (\%) & 1.9 & 2.1 & 3.7 & 2.2 \\
& $(18.1)$ & $(19.6)$ & $(28.7)$ & $(22.4)$ \\
Protein* (\%) & 7.0 & 7.2 & 7.1 & 6.9 \\
& $(66.7)$ & $(67.3)$ & $(55.0)$ & $(70.4)$ \\
Ash* $(\%)$ & 0.5 & 1.1 & 0.6 & 0.6 \\
& $(4.8)$ & $(10.3)$ & $(4.7)$ & $(6.1)$ \\
\hline
\end{tabular}

* Values in parenthesis indicate weight $\%$ in dry matter basis.

the end of rearing were $410 \mathrm{~g}$ (WY yeast) and $395 \mathrm{~g}$ (BY yeast), respectively.

\section{Proximate Composition}

The proximate composition of rotifer fed on WY yeast showed higher ash content than that of rotifers fed on BY yeast, $\omega$-yeast and marine chlorella, but similar moisture, protein and lipid contents to those of groups fed on BY yeast and marine chlorella (Table 2). On the other hand, rotifer reared with $\omega$-yeast showed high lipid and low protein contents as compared with those of rotifers reared with WY yeast, BY yeast and marine chlorella.

\section{Fatty Acid Composition}

As shown in Table 3, the percentage of $\omega^{3}$ HUFA in total fatty acids of lipid from rotifer reared with WY yeast was similar to that of BY group, but lower than those of rotifers reared with $\omega$-yeast and marine chlorella. 
Table 3. Fatty acid compositions in lipids of rotifers fed on baker's yeast (BY), WY, $\omega$-yeast $(\omega Y)$ and marine chlorella (C)

\begin{tabular}{lcccc}
\hline \hline \multirow{4}{*}{ Fatty acid } & \multicolumn{5}{c}{ Rotifer fed on } \\
\cline { 2 - 5 } & BY & WY & $\omega Y$ & C \\
\hline $12: 0$ & 0.7 & 0.2 & 0.3 & 1.5 \\
$13: 0$ & 0.5 & 0.2 & 0.2 & 1.5 \\
$14: 0$ & 1.6 & 1.6 & 3.1 & 3.9 \\
$15: 0$ & 0.7 & 0.8 & 0.9 & 1.8 \\
$16: 0$ & 6.3 & 7.1 & 11.1 & 21.5 \\
$16: 1 \omega 7$ & 18.3 & 17.5 & 13.7 & 10.2 \\
$18: 0$ & 5.4 & 5.7 & 6.8 & 3.7 \\
$18: 1 \omega 9$ & 31.0 & 31.6 & 24.9 & 8.9 \\
$18: 2 \omega 6$ & 8.9 & 7.9 & 2.6 & 4.9 \\
$18: 2 \omega 4$ & 0.8 & 1.1 & 0.4 & 0.9 \\
$18: 3 \omega 3$ & 1.2 & 1.4 & 1.3 & 1.4 \\
$20: 1$ & 4.5 & 5.5 & 6.7 & 2.6 \\
$20: 2 \omega 9$ & tr & 0.8 & 0.4 & 0.7 \\
$20: 2 \omega 6$ & 2.6 & 2.6 & 0.1 & tr \\
$20: 3 \omega 3$ & 0.5 & 0.9 & 0.5 & 1.8 \\
$20: 4 \omega 3$ & 1.1 & 1.2 & 1.2 & 4.4 \\
$20: 5 \omega 3$ & 1.1 & 1.2 & 5.0 & 13.5 \\
$22: 1$ & 2.5 & 2.9 & 4.7 & 2.4 \\
$22: 4 \omega 6$ & 1.1 & 0.7 & 1.5 & 2.4 \\
$22: 5 \omega 6$ & 2.3 & 1.5 & 1.2 & 7.1 \\
$22: 5 \omega 3$ & - & 0.4 & 1.6 & - \\
$22: 6 \omega 3$ & - & - & 4.7 & - \\
\hline$\Sigma \omega 3$ HUFA & 2.7 & 3.7 & 13.0 & 19.7 \\
\hline & & & & \\
\hline
\end{tabular}

In the present study, no difference in growth was found between the rotifers reared with WY and BY yeasts. The proximate composition of rotifer fed on WY yeast was also similar to that of BY and marine chlorella groups. These findings indicate that WY yeast can be used as a feed for rotifer. However, the $\omega 3$ HUFA content of rotifer fed on WY yeast was markedly low, which was due to the low content of $\omega 3$ HUFA in WY yeast. The nutritive value of rotifer as a feed for fish larvae depends on the $\omega 3$ HUFA content of rotifer. ${ }^{\theta)}$ Accordingly, it is necessary that WY yeast is supplemented with $\omega 3$ HUFA or cultured secondarily with marine chlorella before it is fed to rotifer.

\section{References}

1) M. A. Hossain, M. Furuichi, and Y. Yone: Nippon Suisan Gakkaishi, 54, 469-471 (1988).

2) M. A. Hossain, M. Furuichi, and Y. Yone: Nippon Suisan Gakkaishi, 54, 2113-2115 (1988).

3) O. Imada, Y. Kageyama, T. Watanabe, C. Kitajima, S. Fujita, and Y. Yone: Nippon Suisan Gakkaishi, 45, 955-959 (1979).

4) Y. Yone, M. A. Hossain, M. Furuichi, and F. Kato: Nippon Suisan Gakkaishi, 52, 549-552 (1986).

5) M. A. Hossain, M. Furuichi, and Y. Yone: Nippon Suisan Gakkaishi, 53, 1629-1632 (1987).

6) T. Watanabe, F. Oowa, C. Kitajima, S. Fujita, and Y. Yone: Nippon Suisan Gakkaishi, 45, 883-889 (1979). 